NASA Technical Memorandum 103185

AIAA-90-2751

\title{
Integrated Controls and Health Monitoring for Chemical Transfer Propulsion
}

Marc G. Millis

Lewis Research Center

Cleveland, Ohio

and

Michael P. Binder

Sverdrup Technology, Inc.

Lewis Research Center Group

Brook Park, Ohio

Prepared for the

26th Joint Propulsion Conference

cosponsored by the AIAA, SAE, ASME, and ASEE

Orlando, Florida, July 16-18, 1990

\section{N/SA}

(NASA-TM-103183) INTEGRATEO CONTPOLS AND

N90-25178

HEALTH MONITORING FOR CHEMICAL TRANSFER

PROPULSION (NASA) $12 \mathrm{p}$

$C S C L \quad 223$ 


\title{
INTEGRATED CONTROLS AND HEALTH YONITORING FOR CHEMICAL TRANSFER PROPULSION
}

\author{
Marc G. Millis \\ National Aeronautics and Space Administration \\ Lewis Research Center \\ Cleveland, Ohio 44135
}

and

Michael P. Binder

Sverdrup Technology, Inc.

Lew is Research Center Group

Brook Park, Ohio 44142

\section{Abstract}

VASA is reviewing various propulsion technologies for exploring space. This paper examines the requi rements for one enabling propulsion technology: Integrated Controls and Heal th Monitoring (ICHM) for Chemical Transfer Propulsion (CTP). Functional requirements for a CTP-ICHM system are proposed from tentative mission scenarios, vehicle configurations, CTP specifications, and technical feasibility. These CTP-ICHM requirements go beyond traditional reliable operation and emergency shut of $f$ control to include (1) enhanced mission flexibility, (2) continuously variable throttling, (3) tank-head start control, (4) automated prestart and postshut of $f$ engine check, (5) monitoring of space exposure degradation, and (6) product evolution flexibility. Technology development plans are also di scussed.

\section{Int roduction}

Before a lunar base can be built as a stepping stone to Mars, new space vehicles must be developed These vehicles will be space based, reusable, human rated, and cont inuously throttleable. The candidate baseline propulsion for these vehicles is a cryogenic hydrogen-oxygen expander-cycle rocket engine, referred to as the "Chemical Transfer Propulsion" (CTP) engine.

Because these engines must perform a number of different mission duties, including lunar descent, and because they must perform repeatedly and reliably with less maintenance support than existing flight-proven technology, a substantial control and health-monitoring system is required for these engines. Integrated Controls and Health Monitoring (ICHM) technology is being investigated to provide these features for CTP engines. The goals of the ICHM system are to ensure engine reliability, reduce or eliminate the need for in-space inspection and maintenance, and provide the required mission flexibility.

New technologies have emerged which can be applied to CTP-ICHM designs. Advanced miniaturized sensors, fiber optics, artificial intelligence, expert systems, neural networks, and advanced rocket engine modeling make more sophisticated monitoring and control systems feasible.

One of the challenges presently facing the application of these emerging technologies to a CTP-ICHM system is the fact that the system requirements and technological feasibility are uncertain. To date, the correlation between ICHM requirements and the specific missions, vehicles, and transporta$t i o n$ infrastructure has not been sufficiently defined to specify the CTP-ICHM system for the lunar missions. Furthermore, the capabilities of the emerging technologies have not been adequately demonstrated in rocket engine systems to allow the optimum ICHM system technology to be selected.

This paper addresses this challenge by first comparing the present mission plans with general ICHM requirements and then highlighting possible tradeoffs. Because the lunar missions and their associated vehicles will precede the Martian missions, this paper focuses on the lunar missions. On the basis of the likely mission requirements, CTP-ICHM minimum and growth features are proposed to distinguish between enabling and enhancingevolving capabilities. Continuing efforts to further refine these features into a CTP-ICHM system definition are described along with recommendations for future studies to identify the optimum mix of ICHM features and mission, infrastructure, and vehicle features. Recommendations for future work to advance the appropriate ICHM technology are also presented.

\section{Mission-Driven Requi rements}

One lunar mission being considered would use two types of space-based, reusable vehicles: a lunar transfer vehicle (LTV) and a lunar excursion vehicle (LEV) ("Space Transfer Vehicle Concepts and Requirements Quarterly Progress Presentations," NASA Contract NAS8-37856. Martin Marietta Corp.; and "Space Transfer Vehicle Concepts and Requirements Quarterly Progress Presentations, "NASA Contract NAS8-37855, Boeing terospace Co.). The LTV's would ferry payload and crew between lowEarth orbit (LEO) and lunar orbit. They would make the initial delivery of LEV's into lunar orbit and subsequent deliveries of LEV propellant. The LEV's would ferry payload and crew between lunar orbit and the lunar surface.

Vehicle concepts and performance requirements have been identif ied by various studies (Martin Marietta and Boeing Aerospace reports and Refs. I and 2) and cont inue to be revised and refined. A representative vehicle configuration is shown in Fig. 1. Corresponding engine requirements are listed in Table I.

According to these plans, the engines will encounter a greater variety of duties and a more hostile base and operating environoent than any previous rocket engine, thus requiring control and mon$i$ toring systems that are unprecedented in rocket 
technology. The ICHM system must satisfy these requirements in addition to meeting the traditional goals of reliable operation and emergency shutdown fault response. The requirements that need to be quantified in order to guide the configuration and development of the CTP-ICHM system for the lunar rissions are sumarized in Table II. General ICHM features to meet the mission requirements are described next.

\section{Space-Based Operation}

Space-based operation imposes the following three constraints: zero gravity, limited support facilities, and space hazards exposure. In addition to these three constraints, the consequences of a failure in the isolation of space compel the use of dependable vehicles and reliable failure prediction. Zero-gravity operation requires engine pumps that are capable of starting from tank-head pressure. Limited facility support necessitates built-in engine checks to verify the engine's operational integrity. Manual inspections cannot be performed prior to every engine start (in lunar orbit, for example). Checkout operations, such as prefiring the engine, may also be impractical because of the difficulty of ensuring that the vehicle remains in a safe orbit in the event of an anomalous start. Some degree of prestart readiness verification must, therefore, be built into the engine. Because the engines will be stored in space for extended periods of time, the engine and ICHM system must survive degradation from exposure to numerous space hazards such as space debris, monatomic oxygen, and radiation.

\section{Reusable Engines}

The specification of reusable engines imposes several requirements: sustained rellability without major service, built-in engine diagnostics, tolerance to long-duration space exposure, missionto-mission control flexibility, and (possibly) engine life prediction.

The requirement of multiple flights without major service might increase the difficulty of sustaining human-rated reliability. In the absence of manual inspection facilities, the engine diagnostics would have to be built in and presumably performed between flights. Spaced-based engines with long operational lives would face increased exposure to space hazards. Because one engine and vehicle configuration would be used for many mission duties, the engine controller would have to accomnodate multiple thrust-versus-time profiles and, possibly, different levels of critical reliability. Because it is potentially more economical to use the engines to the limit of their service life, it is highly desirable to be able to predict the remaining life of an engine on the basis of measured parameters.

\section{Deep-Throttling Engines}

It is estimated that lunar descent maneuvering will require a throttling range of at least 10:1 (100 to 10 percent of maximum thrust) and could require as much as a 20:1 span of continuously variable, on-demand, thrust control. The required timerate-of-change of this throttling is, at present, unknown. In addition to descent throttling, basic expander-cycle startup involves tank-head-idle and pumped-idle operation.
Presently, such start modes and 10:1 throttling are considered feasible for expander-cycle engines. 3 The estimated maximum time-rate-ofchange for throttling is 10 to 100 percent in 4 sec, 100 to 10 percent in $3 \mathrm{sec}$, and 10 percent changes in $0.3 \mathrm{sec}$ (video conference between Aerojet TechSystems' Expander Cycle Engine and Instrumentation group and NASA Lewis Research Center's Space Vehicle Propulsion Branch, Sacramento, $\mathrm{CA}$, and Cleveland, $\mathrm{OH}$, Dec. 20, 1989). Such substantial throttling requires closed-loop control.

\section{Product Evolution}

During the product life of LTV's and LEV's, alternative missions and improvements in technology will arise. To accommodate these changes, since "developing a score of specialized vehicles is not feasible," 2 product improvement flexibility must be designed in by "using common vehicle systems and subsystems where possible." 2 This requires a greater degree of modularity than is presently used.

\section{Mission and Technology Tradeof $\mathrm{fs}$}

The specific missions, vehicles, and supporting infrastructure definitions will alter the specific ICHM requirements. Conversely. the feasibility and cost of ICHM features will affect the mission, vehicle, and infrastructure options. Many of the previously discussed CTP and ICHM requirements can be eliminated or substantially reduced by increasing the capabilities of the vehicles or infrastructure. Some examples of these tradeof $f s$ follow:

\section{Vehicle Tradeoffs (for both LTV and LEV)}

The performance of a vehicle is a composite of all its systems. With respect to propulsion, the complementary vehicle systems are the main engines and the vehicle's auxiliary or attitude control propulsion. The degree to which each of these systems contribute to the vehicle's total propulsion performance is subject to tradeoff analyses. More specific examples of CTP-ICHM tradeoff issues follow:

(1) Thrust control accuracy versus more substantial attitude control propulsion

(2) Control flexibility (throttling and gimballing) versus more substantia! auxiliary propulsion capable of compensating for an engine-out situation

(3) Control flexibility (nozzle position and thrust/time control) versus vehicle aerobrake methods

(4) Mixture ratio control accuracy versus contingency propellant

\section{Space-Basing Tradeof $\mathrm{s}$}

(1) Built-in engine self-inspection versus comprehensive, external, in-space inspection facilities available at all mission nodes: including inspection tools (plume spectrometers; optical leak detectors; and probes for inspecting injectors, chamber, and nozzle), astronaut time, service robots, and tools and spares storage 
(2) Reliability and fault tolerance versus preparation for contingencies (redundancy, auxiliary propulsion, mission node havens, etc.)

\section{Reusability Tradeof $\mathrm{fs}$}

(1) Reliability and fault tolerance versus inspace repair facility sophistication

(2) Human-rated reliability for all missions versus reduced requirements for unmanned missions (The first and last few uses of the engines would carry greater risks. Coordinating these events with less critical, unmanned missions could greatly reduce the degree of overall required reliability.)

(3) Heal th-monitoring sophistication (including space exposure tolerance and monitoring) versus intentional underutilization of the engine

(4) Monitoring sophistication to predict remaining life versus scheduled replacement

\section{Deep-Thrott ling Tradeof fs}

(1) Extended throttling control range versus other engine requirements (reliability, performance, and operational I ife)

(2) Fast, stable time-rate-of-change for descent throttling versus different descent profiles or auxiliary propulsion compensation (It is also useful to know if prolonged use at any particular thrust setting is anticipated.)

\section{Product Evolution Tradeof $s$}

CTP-ICHM modularity, flexibility, growth contingency, and data base archiving would have to be weighed against the development of several different engines and vehicles.

\section{Baseline CTP-ICHM Features}

Recognizing the range of tradeoff options, we now present a baseline set of qualitative CTP-ICHM requirements to provide a reference point for conducting tradeoff studies and for focusing technology programs. These baseline requirements assume the absence of extensive in-space maintenance or inspec$t i$ and assume that the entire engine is the line replaceable unit (LRU). A "minimum plus growth" approach is used to define this baseline in order to distinguish between enabling and enhancing technologies. The rationality of these baseline definitions was checked with three major rocket engine contractors during video conference discussions (video conference between Aerojet TechSystems' Expander Cycle Engine and Instrumentation group and NASA Lew is Research Center's Space Vehicle Propulsion Branch, Sacramento, CA, and Cleveland, OH, Dec. 20, 1989; video conference between Rockwell International, Rocketdyne Division's Expander Cycle Engine and Instrumentation group and NASA Lewis Research Center's Space Vehicle Propulsion Branch, Canoga Park, $C A$, and Cleveland, $O H$, Jan. 11, 1990; and video conference between United Technologies, Pratt \& Whitney Division's Expander Cycle Engine and Instrumentation group and NASA Lewis Research Center's Space Vehicle Propuls ion Branch, West Palm Beach, CA, and

Cleveland, $\mathrm{OH}$, Jan. 19, 1990).

\section{CTP-ICHM Minimum Features}

"Minimum" features are defined as features that are essential given the LTV and LEV mission requirements for man-rated reliability of a spacebased, reusable, throttleable, expander-cycle engine. One minimal feature is that the system must be capable of expansion to incorporate the viable and useful growth features. The minimal CTP-ICHM features include

(1) Closed-loop control during all engine modes (prestart, startup, steady state, throttling, and shutdown)

(2) Basic expander-cycle operation including tank-head start and idle

(3) Emergency shutdown control

(4) 10:1 continuously variable throttling

(5) Built-in automated prestart readiness check (based on engine sensors)

(6) Automated post-shutdown engine check (based on engine sensors)

(7) Space exposure tolerance and monitoring

(8) Engine-out thrust compensation (gimballing, and rapid, accurate thrust change)

(9) Growth flexibility

\section{CTP-ICHM Growth Features}

The "growth" features represent those technological abilities that are highly desirable but not essential. These features allow flexibility to accommodate the changing scope of mission duties, to incorporate new technologies which enhance mission capabilities, and to incorporate product improvements. These growth features include

(1) Automated pre-mission inspection (which would assess the ability to complete the entire mission, in addition to the minimum prestart readiness check)

(2) Real-time diagnostics during firing

(3) Adaptive controls based on real-time diagnostics to optimize the choice of choice engine reliability, engine performance, or engine longevity

(4) Flexibility to incorporate emerging technologies as they become flight qualified

(5) Oxidizer-rich operation control to take advantage of lunar-derived oxygen

(6) Automated life prediction (based on sensor data)

Inherent in the mission and technology tradeof $\mathrm{s}$ listed previously, is the uncertain distinction between "enabling" and "enhancing" technology; hence, study results may shift the distinction 
between minimum and growth features. In addition, if some of the minimum or growth features listed are found to be infeasible or prohibitively expensive, alternative mission options may be necessary. The results of the studies will also translate these features into quantitative design spec $i f$ ications.

\section{Technology Readiness Assessment}

Before tradeoff studies can effectively identify optimum ICHM specifications, or mission, vehicle, or infrastructure features, more data on the cost and feasibility of ICHM technology are required. To provide those data, two rocket engine contractors were asked to assess the technology readiness and remaining development cost of a minimum ICHM system. These assessments were to be based on the contractors' preliminary designs of the orbit transfer vehicle (OTV) rocket engines and on representative mission assumptions. These tasks are due to be completed in August 1990. The details of these tasks, reference technology, mission assumptions, and preliminary results are described next.

\section{Assessment Goals}

The contractors" tasks are to (1) specify the minimum features of the OTV engine ICHM system, (2) identify the necessary system elements to provide those features, (3) estimate the technology readiness of each system element, (4) estimate the remaining development cost to demonstrate the system in a simulated envi ronment by 1996 , and (5) estimate the technology readiness, cost, and benefit of including potential growth features. The rating scale for technology readiness is the same as that used by the NASA office of Exploration for comparing technology options, and is listed in Table III.

\section{Technology Reference}

CTP technology is a continuation and refinement of the similar, but smaller scale, OTV rocket engine program in progress since the early 1980's. ${ }^{4}$ The original driving mission for the OTV was manned low-Earth orbit to geosynchronous orbit transfer (LEO-GEO), and the OTV engine was targeted to be a reusable, space-based cryogenic hydrogen-oxygen expander-cycle engine with $33 \mathrm{kN}$ (7500 lb) thrust, a high-performance specific impulse of $485 \mathrm{sec}$, and a $10: 1$ throttle ratio. Work progressed to the point of developing preliminary engine designs and testing some components. Although not identical to the CTP engine, the preliminary OTV engine designs provide specific hardware examples that allow for more realistic technology assessments.

\section{Assessment Assumptions}

The mission assumptions for the OTV engine technology assessment are similar to the CTP requirements of human-rated reliability and continuously variable throttling. With respect to space basing, the assumptions were constrained to having no facilities for routine engine inspections and having the in-space LRU be the entire engine. These assumptions contrast other studies that assumed a more extensive space-based maintenance infrastructure. 5 These contrasts should help highlight the impact and benefits of built-in engine inspection and whole-engine replacement .

\section{Preliminary Results}

One of the engine contractors has completed the first three subtasks - namely the identification of minimal features, system elements, and estimates of technology readiness for each element ("Yonthly Technical Progress Reports for the Orbit Transfer Rocket Engine Technology Program. Reports 23772-M-80, 81, and 82," NASA Contract NAS3-23772, Task E.7, Aerojet TechSystems, Sacramento, CA, Jan.-Mar. 1990.) These items are categorized according to the following engine operation cycles:

\section{(1) Preflight readiness assessment}

(2) Engine startup and tank-head idle control

(3) Pumped-idle control

(4) Main stage and engine throttling control

(5) Engine shutdown control

(6) Safety monitoring

(7) Diagnostic monitoring

(8) Condition monitoring

(9) Post-flight condition assessment

(10) Vehicle interfacing

(11) Engine storage, removal, and replacement

Because of the required reliability and minimal operation support for the engine, the contractor concluded that the minimal features should include real-time engine diagnostics to detect anomalies or of $f$-nominal performance and adaptive control to provide online system adjustments. These functions are necessarily performed by using engine parameter estimation, a real-time engine model, and redundant measurements derived from analysis of other parameters.

The individual elements to provide these features cover the full span of estimated technology readiness, from level 1 to level 7 (Table III) The diagnostic sof tware typically ranked level 2 , the control software typically ranked level 3, the sensors predominately ranked either level 7 or 4 , and the other hardware levels predominately ranked level 4 or 5 . The total ICHM syster readiness was not ranked by the contractor, but it falls in the range of readiness level 2 or 3 because a full ICHM system breadboard has not yet been demonstrated in the laboratory.

At the time of writing this paper, there were no available estimates of the remaining development cost to bring all the necessary elements and total system to readiness level 6 by 1996 .

\section{Present and Future CTP-ICHM Technology Programs}

Focused research continues to advance CTP and ICHM technology. CTP programs include the Advanced Expander-Cycle Test Bed (AETB), generalized system 
modeling, and deep-throttling studies. The nearterm ICHM activities include the previously described technology assessment tasks, automated prestart readiness assessments, space environment hazards survey, and ICHM system f ramework specification.

\section{Advanced Expander-Cycle Test Bed}

The most notewor thy segment of CTP work is the Advanced Expander-Cycle Test Bed (AETB) engine program. The AETB is a complete experimental engine system that is targeted to be delivered to the NASA Lewis Research Center in mid 1993. That engine will be used as the systems technology test bed and, later, as a system on which advanced technologies (including ICHM) can reach readiness level 6 (Table III), and thus be considered as technology ready for an engine development program. The information acquired from these activities will provide the technology data base for the development of the next generation of space engines.

\section{CTP Generalized System Modeling}

Engine system modeling is being explored for design performance verification analysis of cycle, throttling, and control options. This modeling will consist of steady-state and transient analysis and will be used to analyze cycle options and various engine control schemes. These models could also be used for failure modeling and to help train neural nets and expert system knowledge bases that might be used in a heal th-monitoring system. The exact configuration, software, and features of these models have not yet been chosen.

\section{CTP Throttling Study}

Studies will assess the effects of and alternatives to $20: 1$ throttling of an expander-cycle engine and will perform parametric analysis to determine how deep throttling affects overall engine performance.

\section{Automated Prestart Readiness Methods}

A study is underway to define and evaluate various methods of performing an automated prestart readiness check. These methods span a range of sophistication from actual test firing, to an entirely static checkout (no physical cycling of any components). The technology readiness and remaining development cost of these methods will be estimated. This information will be useful in tradeoff studies assessing the degree of spacebased external inspection support versus buil $t-i n$ self-inspection.

\section{Space Environment Hazards Survey}

The variety of space hazards that are likely to be encountered in Earth-Moon mission regimes are being surveyed. This information will be used to indicate which hazards will require attention in engine system designs and ICHM functions. Typical space hazards include space debris, monatomic oxygen, radiation, and thermal gradients.

\section{ICHM Framework Specification}

A system $f$ ramework is being defined to determine the interaction of sensor data, monitoring functions, and control algorithms. ${ }^{6}$ The frame- work will describe the different functions, algorithns, and component interactions (data and information flow) within the ICHM system. The implementation of this framework in a systen architecture is also planned. This architecture is a candidate for demonstration on the AETB system.

\section{Concurrent Heal th Monitoring or Control Technology Programs}

Technology applicable to CTP-ICHM is being pursued in several other programs: the orbit transfer vehicle (OTV), the Civil Space Technology Initiative, Earth to Orbit (CSTI-ETO), the Advanced Launch System (ALS), and aeronautical propulsion. The applicability of these other programs is limited by the degree of similarity to the CTP configurations (small size) and missions (space based, reusable, and continuously throttleable). These parallel efforts are summarized next.

\section{OTV Rocket Engine Technology}

The program most applicable to CTP is the OTV program. As described before, the OTV's require a human-rated, reusable, space-based, 10:1 throttleable, expander-cycle engine that is approximately the same size as CTP engines and has practically the same operational environment. Because of programmatic constraints, the ICHM work on this engine has focused mainly on improving small, reliable sensors.7-10 This sensor work is directly applicable to CTP and could also apply to other programs. ICHM system definitions were out lined, 3 and that work continues today in the form of the technology readiness assessments previously described.

\section{CSTI-ETO Technology}

The CSTI program is developing candidate heal th-monitoring methods for ETO engines such as the Space Shut te Main Engine (SSME) ("ETO Propulsion Progran-FY90, Validation Program Tasks Descriptions and Schedules," and "ETO Propulsion Program - FY90, Technology Acquisiti on Tasks Descriptions and Schedules," NASA Headquarters, CODE RP, unpublished reports, Jan. 1990.) Because the SSME is currently in service, there is significant hardware test experience on which to base and evaluate health assessment methods. However.

because the mission envelope and hardware conf igurations of the SSME are different from those for CTP, the SSME work will not be readily transferable to CTP. The same general approaches and tools might be used, but they would have to be adapted to the specific configurations and mission constraints of the CTP-ICHM system.

For example, the sof tware work for the SSVE has concentrated less on advanced control methods because the SSME is a flight-qualified design with limited flexibility to incorporate additional control valves. The critical monitoring areas are also different; the SSME turbines encounter larger thermal transients, and the CTP engines have higher pump speeds. Miniaturization of sensors is less critical in the SSME than in CTP. Also, many of the diagnostic tools such as expert system analysis and leak detection systems are designed for human-tended use in ground-based facilities and may not apply to automated systems for the vacuum of space. The relevant differences between the SSME and CTP systems are outlined in Table IV. 
Advanced Launch System

The ALS program is also making a substantial effort to develop controls and heal th-monitoring devices. The ALS is similar to the SSWE with respect to the Earth-to-orbit operational envelope. It is similar to CTP with respect to having minimal hardware experience and data bases. The sensor selection methodologies for ALS research and ALS investigations into processors for use in harsh envir ronments are applicable to CTP-ICHM.

\section{Aeronautical Engine Systems}

The aircraft engine industry has a rich history in engine monitoring and control. It has developed a number of useful design, simulation, and maintenance tools based on extensive experience. It is also developing advanced control, detection, and diagnostic algorithms; advanced sensors; and fiberoptic cabling systems.

The differences between aeronautical engines and CTP engines are great, thus limiting the direct application of these systems. The general approaches such as system modularity and developing general purpose tools, however, may be applied to defining the CTP-ICHM framework and architecture. Advanced engine control methods and control and monitoring system design methods are the most applicable technologies.

\section{Recommended Future Work}

The challenges facing the development of ICHM technology for CTP can be categorized into four groups: system requirement $t r a d e o f f s$, technology selection tradeoffs, emerging technologies, and technology demonstrations. System requirement tradeoffs refer to resolving the mission versus technology tradeoffs listed previously. Technology selection tradeof $f$ refer to resolving the best methods to satisfy ICHM requirements, including technology tradeoff studies, design tools, and testing tools. Emerging technologies refer to the continued exploration of technologies that are likely to be useful to CTP-ICHM systems, such as miniaturized sensors and advanced sof tware. Technology demonstrations refer to the actual use of emerging technologies in engine components and systems necessary to prove their viability for application in future engines. Tasks being considered or planned for each of these categories are outlined next.

\section{System Requirement Tradeoffs}

Further definition of CTP-ICHM requirements is needed to focus the technology development. This includes performing tradeof $f$ analyses on the complementary systems listed earlier. These tradeoff studies are also necessary to identify effects on mission, infrastructure, and vehicle design options. The results of the ICHM technology assessment tasks will support these tradeoff studies. Examples of such studies follow:

(1) Vehicle, propulsion system, and engine performance tradeoffs to quantify system specifications, such as those listed in Table II, and to identify ICHM requirements for vehicle designs
(2) Autonomous monitoring and fault accommodat i on versus spaced-based inspection and repair inf rastructure tradeoffs will deternine the optimum methods for performing space-based readiness inspections and for responding to engine faults

(3) Reliability and performance versus reusability tradeoffs

(4) Vehicle, propulsion system, and engine interface tradeoffs to optimize the effectiveness of the vehicle and engine control and the monitoring hierarchy

(5) Space hazards assessments to address monitoring and degradation tolerance of anticipated critical hazards

Technology Selection Tradeof $\mathrm{s}$

(1) On-board versus ground-based diagnostic analys is

(2) Direct-sensing versus inferred conditions

(3) Sensor reliability versus redundancy

\section{CTP-[CHM Design Tools}

In order to define and evaluate ICHM frameworks and architectures, a number of analys is tools are required in addition to engine design models. Examples of these tools follow:

(1) Modular, steady-state engine simula$t$ ion, where each component and subsystem is programmed as a separate subroutine so that a number of different engine configurations can be modeled

(2) Dynamic engine simulation for analyzing various nominal control and monitoring methods, including throttling control

(3) Failure and degradation simulation that can be linked to the dynamic engine simulation to analyze fault response control and monitoring methods

(4) Real-time dynamic engine model for parallel use with the test bed engine

\section{Data Base Management Tools}

AETB and focused technology testing will generate much data that must be analyzed between tests and made available for more detailed analysis. A dedicated data acquisition, analysis, and archiving system will be needed to accompany the tests to ensure continuity of data recording and access throughout the engine use period.

In addition to the data base for testing, an archiving system may be required to track the design evolution of the CTP engines. This archiving system will make it possible to knowledgeably refine these engines for the evolving mission applications preently being considered, such as Mars transfer and ascent and descent propulsion. 


\section{Emerging Technology Tasks}

Because of their potential benefits, several technologies deserve continued attention so that they can be used in future engines.

Hardware. Some examples of useful hardware technology follow:

(1) Miniaturized sensors for use in the relatively small CTP hardware, such as shaft dynamic sensors and bearing deflectometers

(2) External sensor systems, such as plume spectrometers and optical or distributed propellant leak-detection sensors

(3) Fast cryogenic valves to provide control

(4) Alternative data harnesses, such as fiber optics, to provide fast data-rate capabilities for advanced data processing

(5) Mass data storage devices to contain the on-board engine analysis programs and sensor data

Sof tware. Various sof tware tools could enable or enhance ICHM, and are likely to be contained within specific architectural elements. These tools are likely to include qualitative reasoning, parameter estimation, linear and nonlinear regression, Kalman filtering, neural networks, and expert sys tems.

\section{Technology Demonstration Tasks}

Before any of the emerging technologies can be considered for inclusion in the next generation of spacecraft engines, they must be demonstrated with an engine system in a simulated environment technology level 6 . The approximate deadline for level 6 is 1996 or 1997 . Therefore, the emerging technologies should be demonstrated as soon as possible so that testing of the full CTP-ICHM system is not delayed. Some sample demonstration tasks follow:

Monitoring Software. The emerging software techniques should be demonstrated on actual component test stands. This may take the form of augmenting a turbopump seal test stand with a parallel heal th-monitoring and analysis system intended to provide real-time fault diagnostics.

Advanced Sensors. Emerging sensor technology should be used in rocket engine component tests to demonstrate the sensors' capability to operate in actual rocket engine environments.

ICHM systems and subsystems. Again, in the context of component test stands, integration of advanced sof tware, sensors, and control effectors should be demonstrated successfully before a full ICHM system is demonstrated in AETB testing.

\section{Concluding Remarks}

Because future Chemical Transfer Propulsion (CTP) engines must be human rated, continuously throttleable, reusable, and space based; they must have more sophisticated Integrated Controls and Health Honitoring (ICHM) systems than existing flight-proven technology. The exact correlation between ICHM features and mission, infrastructure, and vehicle specifications is still uncertain. To help define these correlations, this paper examined the association between mission plans and ICHM functional requirements, and described ongoing work to assess the readiness and remaining development cost of the supporting technology.

The main ICHM features are driven by space basing, reusability, throttling, and product evolution. These features include closed-loop control during all phases of engine operation (tank-head start, idle, steady-state thrusting, throttling, and shutof f) and include emergency shutof fault response, 10:1 continuously variable throttling, built-in prestart readiness checkout, automated post-shut of $f$ diagnostics, long-duration space-exposure monitoring and tolerance, and built-in system growth potential.

Anticipated growth features for the ICHM system include the ability to perform automated premission readiness checkouts; incorporate emerging technologies; incorporate changes for alternative mission duties; perform real-time engine diagnostics; use real-time engine diagnostics for adaptive control to optimize engine reliability, performance, or longevity; and estimate the remaining life of the engine.

Technology assessments and tradeoff analyses must be performed to provide the optimum mix of ICHM features and mission options. Two primary examples include engine control accuracy versus substantial auxiliary propulsion and engine-out throttling capacity versus substantial auxiliary propulsion or reduced payload masses. To provide these features, various technologies (such as advanced sensors, valves, and monitoring and control software) must be developed and tested in systern demonstrations.

\section{References}

(1) "Lunar Lander Conceptual Design," Eagle Engineering, Inc., Houston, TX, EEI report 88-181, 1988, NASA CR-172051.

(2) Roberts, B.B. and Bland, D., "Office of Exploration: Exploration Studies Technical Report, Vol. II, Studies Approach and Results," NASA TM-4075-VOL-2, 1988.

(3) Holzmann, W.A. and Hayden, W.R. "Integrated Control and Health Management. Orbit Transfer Rocket Engine Technology Program," ATC-2459-42-1, terojet TechSystems, Sacramento, CA, 1988, NASA CR-182122.

(4) Hannum, N.P., Berkopec, F.D., and Zurawski, R.L., "NASA's Chemical Transfer Propulsion Program for Pathfinder," ALAA Paper 89-2298, July 1989 (AIso, VASA TM-102298).

(5) "Turnaround Operations Analys is for OTV," Vols. I-IV, General Dynamics Space Systems Division, CDSS-SP-87-018-VOL-1, $-2,-3,-4$, Feb. 1988, NASA CR-179316, NASA CR-179317, NASA CR-179318, NASA CR-179319. 
(6) Binder, M. and Millis, M.G., "A Candidate Architecture for Monitoring and Control of Chemical Transfer Propulsion Systems," AIAA Paper 90-1882, 1990

(7) Coleman, P.T., Collins, J.J., and Randall, R.R., "A Dynamic Shaft Position Analyzer for OTVE Condition Monitoring," AIAA Paper 89-2917, July 1989.

(8) Coleman, P.T. and Collins, I.J., "OTVE Turbopump Condition Monitoring, Task E.5;" RI/RD89-214-TASK-E.5, Rockwell International Corp., Canoga Park, CA, 1989, NASA CR-182274.
(9) Szemenyei, B.L., Nelson, R.S., and Barkhoudarian, S., "OTVE Combustor Wall Condition Monitoring," RI/RDBg-212, Rockwell International Corp., Canoga Park, CA 1989, NASA CR-182275.

(10) Collamore, F.N., "Integrated Control and Heal th Monitoring Capacitive Displacement Sensor Development Task. Orbit Transfer Rocket Engine Technology Program," NASA CR-182279, 1989.

TABLE I . - PRELIMINARY CHEMICAL TRANSFER PROPULSION REQUIREMENTS

\begin{tabular}{|c|c|c|}
\hline Requi rements & Lunar Transfer Vehicle & Lunar Excursion Vehicle \\
\hline Engine cycle & $\begin{array}{l}\text { Cryogenic hydrogen- } \\
\text { oxygen expander cycle }\end{array}$ & $\begin{array}{l}\text { Cryogenic hydrogen- } \\
\text { oxygen expander cycle }\end{array}$ \\
\hline $\begin{array}{l}\text { Reliability } \\
\text { requi rement }\end{array}$ & $\begin{array}{l}\text { Human rated, fail } \\
\text { operational, fail safe }\end{array}$ & $\begin{array}{l}\text { Human rated, fail } \\
\text { operational, fail safe }\end{array}$ \\
\hline Operational environment & Space based & Space based \\
\hline $\begin{array}{l}\text { Flights wi thout major } \\
\text { service }\end{array}$ & 5 (including 30 starts) & 5 (including 30 starts) \\
\hline Duration in space & Unknown & Unknown \\
\hline $\begin{array}{l}\text { Number of engines in } \\
\text { cluster }\end{array}$ & 3 or 4 & 4 \\
\hline $\begin{array}{l}\text { Maximum thrust per } \\
\text { engine, } \mathrm{kN} \text { (lb) }\end{array}$ & $\begin{array}{l}90 \text { to } 222 \\
\left(20 \text { to } 50 \times 10^{3}\right) \\
\text { most likely } 111 \\
\left(25 \times 10^{3}\right)\end{array}$ & $\begin{array}{l}53 \text { to } 111 \\
\left(12 \text { to } 25 \times 10^{3}\right) \\
\text { most likely } 111 \\
\left(25 \times 10^{3}\right)\end{array}$ \\
\hline Throttling & $\begin{array}{l}\text { Tank-head idle } \\
\text { Pumped idle } \\
\text { Full thrust }\end{array}$ & $\begin{array}{l}\text { Continuous range: } \\
100 \text { to } 10 \text { percent min } \\
100 \text { to } 5 \text { percent max }\end{array}$ \\
\hline $\begin{array}{l}\text { Maximum specific } \\
\text { impulse, sec, I }\end{array}$ & 480 & 465 \\
\hline Vehicle compatibility & Aerobrake & Short nozzle \\
\hline
\end{tabular}




\section{TABLE II. - CHEMICAL TRANSFER PROPULSION - INTEGRATED CONTROLS AND HEALTH MONITORING (CTP-ICHM) SPECIFICATIONS}

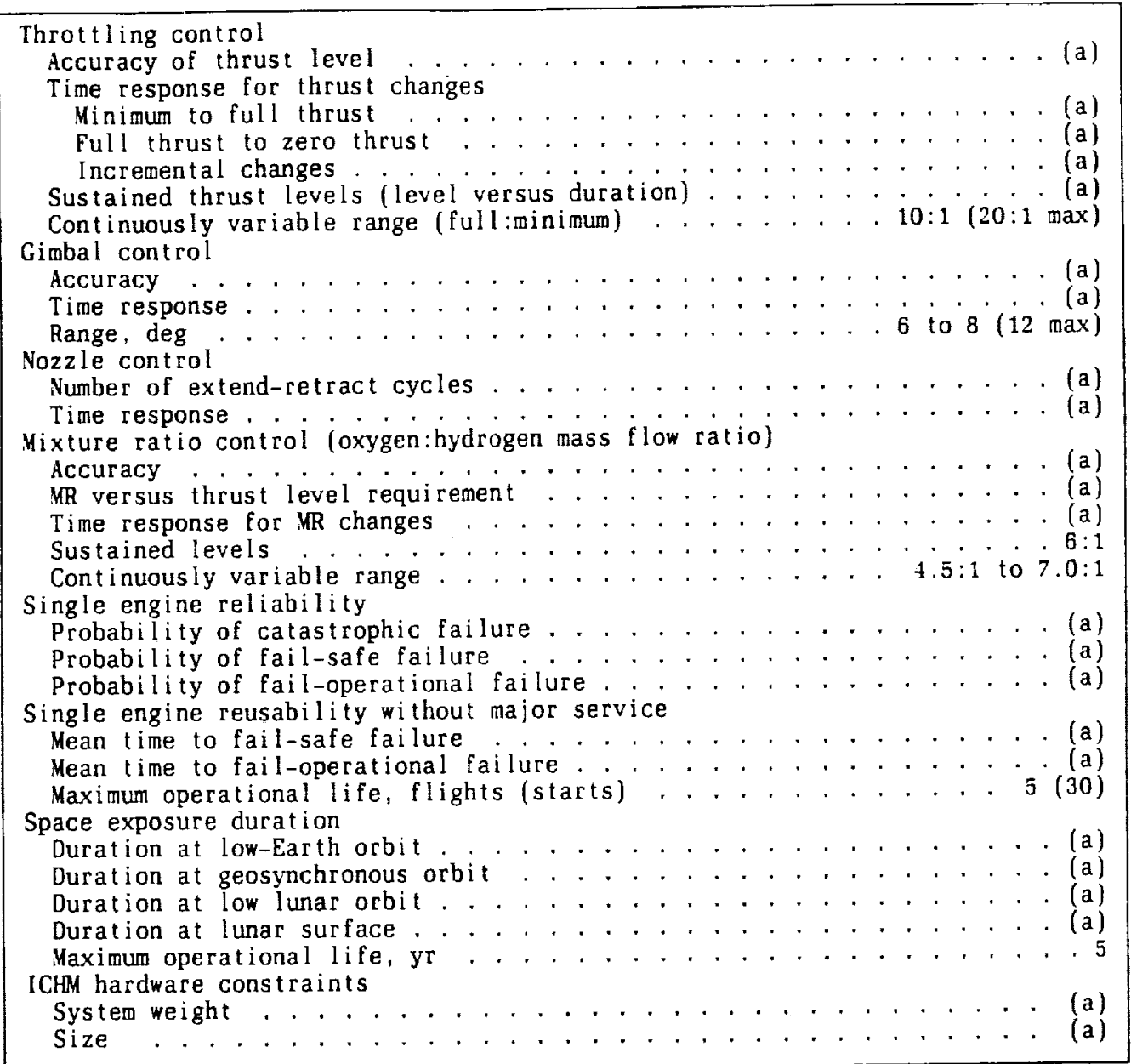

aTo be determined.

TABLE III - - TECHNOLOGY READINESS SCALE

Level 1 - Basic principles observed and reported

Level 2 - Technology concept and application formulated

Level 3 - Analytical and experimental critical function and/or proof of concept

Level 4 - Component and/or breadboard validation in laboratory

Level 5 - Component and/or breadboard demonstration in relevant envi ronment

Level 6 - System validation model demonstrated in simulated environment

Level 7 - System validation model demonstrated in space

Level 8 - Flight-qualified system

Level 9 - Flight-proven system 
TABLE IV. - CRITICAL DIFFERENCES BETWEEN CHEYICAL TRANSFER PROPULSION AND SPACE SHUTTLE MAIN ENGINE

\begin{tabular}{|c|c|c|}
\hline Requi rements & Chemical transfer propulsion & Space Shuttle Kain Engine \\
\hline Engine cycle & $\begin{array}{l}\text { Cryogenic hyrogen-oxygen } \\
\text { expander cycle }\end{array}$ & Staged combustion \\
\hline $\begin{array}{l}\text { Operational data } \\
\text { bases }\end{array}$ & No engine system data & Significant data bases \\
\hline Design flexibility & Requires new technology & Limited control options \\
\hline $\begin{array}{l}\text { Diameter of } \\
\text { turbopump, cm }\end{array}$ & $\sim 10$ & $\sim 70$ \\
\hline Pump speeds, rpa & High $(190000 \max )$ & Moderate $(34000)$ \\
\hline $\begin{array}{l}\text { Substance that } \\
\text { drives turbine }\end{array}$ & Warm fuel or oxidizer & Hot combustion gases \\
\hline $\begin{array}{l}\text { Operational } \\
\text { maintenance }\end{array}$ & $\begin{array}{l}\text { No capability anticipated } \\
\text { for in-space repair }\end{array}$ & $\begin{array}{l}\text { Manually inspected and } \\
\text { repaired between } \\
\text { missions }\end{array}$ \\
\hline Mission profile & Variable & Always Earth to orbit \\
\hline $\begin{array}{l}\text { Duration (and type) } \\
\text { of space exposure }\end{array}$ & $\begin{array}{l}\text { Years (low-Earth orbit, } \\
\text { geosynchronous orbit, } \\
\text { and lunar orbit) }\end{array}$ & Weeks (low-Earth orbit) \\
\hline Throttling & Continuous, up and down & Preprogranmed, discrete \\
\hline
\end{tabular}

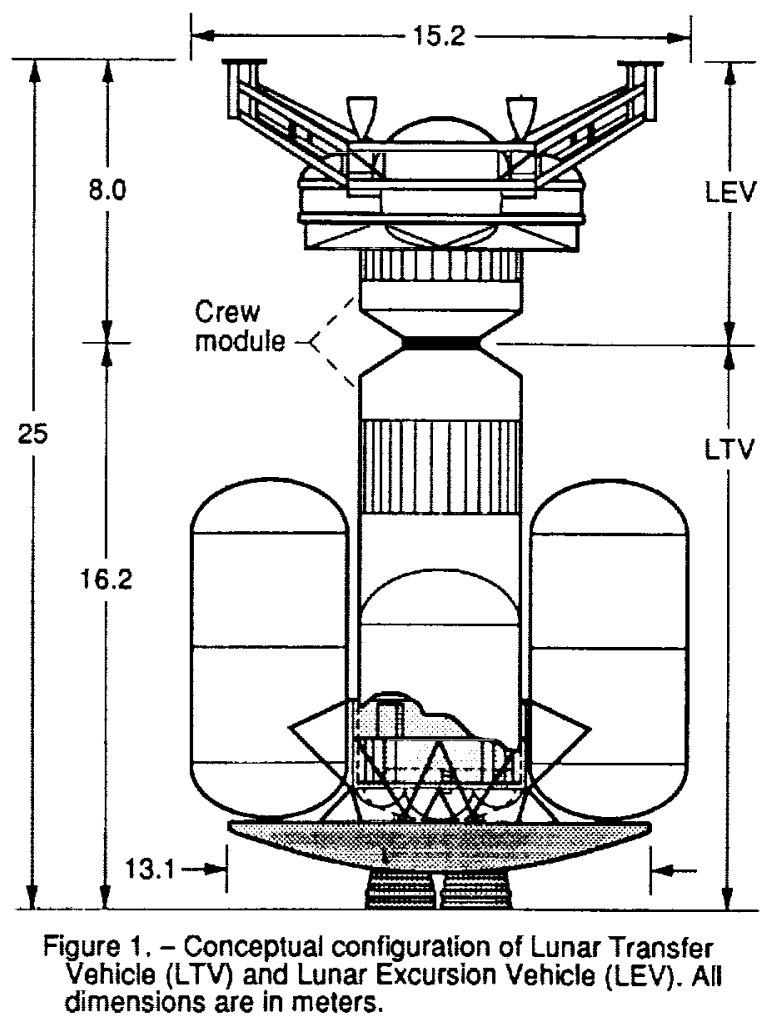




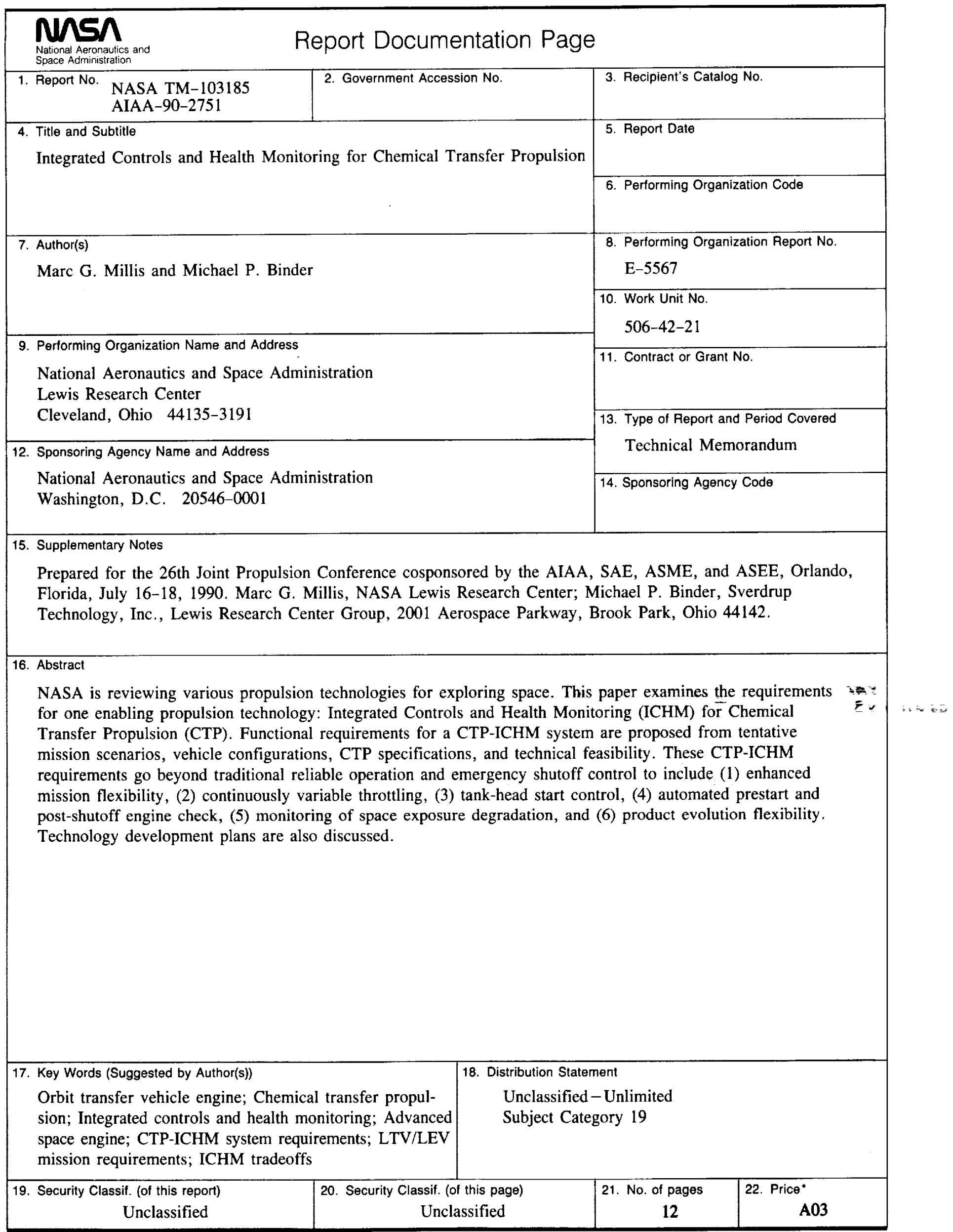




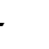

